\title{
APPLICATIONS OF CRYSTALLOGRAPHY TO CHEMISTRY
}

$\mathrm{S}^{\mathrm{B}}$ ECTION B (Chemistry) of the British Association on August 29 devoted a morning session of the annual meeting held in Glasgow to a discussion of the chemical applications of modern crystallography. The meeting was well attended and three papers were presented dealing, respectively, with applications to organic chemistry, inorganic chemistry, and with the packing of molecules in crystals.

In his paper on "The Measurement of Molecules by X-Rays" Prof. J. Monteath Robertson first outlined the classical methods and concepts of organic chemistry by means of which the relative positions in space of all the atoms in many hundreds of thousands of organic molecules have been determined, starting with the fundamental ideas of Kekule and Archibald Scott Couper of Kirkintilloch. In contrast, the X-ray crystallographic method, developed during the past forty-six years, proceeds by direct measurement and calculation from the diffraction pattern. Kekulé's formula for benzene was shown and compared with the latest electron density section evaluated in the plane of the molecule by Prof. E. G. $\mathrm{Cox}^{1}$. This shows a time average of the distribution of electrons, and the atoms stand out as peaks on the contoured diagram. The main cause of the blurring of the atoms in this diagram is the fairly large amplitude of thermal movement that they possess in the crystal even at $-3^{\circ} \mathrm{C}$., the temperature at which the measurements were made. The motion is mainly an oscillation of the whole molecule of amplitude 7-9 deg. about the six-fold axis.

Similar sections of the naphthalene and anthracene molecules were shown, based on a very complete evaluation of the X-ray intensity data ${ }^{2}$. These crystals have higher melting points than benzene, and the thermal movements of the atoms, although still large, are less than in benzene. The definition of the atoms is now so good that the bond-lengths can be estimated to within a few thousandths of an angstrom.

Further elaborate refinements have recently been carried out on these molecules to try to obtain evidence regarding the distribution of the electrons that form the chemical bonds between the atoms. Briefly, the method consists of calculating the theoretical distribution of electrons in an isolated or nonbonded carbon atom. The thermal movement, which smears out the electron distribution, is then carefully calculated from the X-ray intensities. The theoretical atoms, each with its proper thermal movement but non-bonded, are then subtracted from the experimentally observed electron distributions. Any residual electron density may then be attributed to the effect of the chemical bonds. At this limit of refinement the accuracy of the observations (the measured intensities) is not sufficient to yield really conclusive results. But the results which have recently been obtained by D. W. J. Cruickshank ${ }^{3}$ provide fairly definite experimental evidence for a ridge of residual density running around the aromatic rings and along the directions of the chemical bonds. This is in striking agreement with chemical theory for aromatic systems.
In addition to this work on simple molecules, a second and most important application of the X-ray diffraction method is in dealing with new, chemically unknown or incompletely known structures, where the object of the work is not so much extreme accuracy as just to locate the atoms in order to discover the struc. tural formula. Serious problems of phase determination now arise, and the most generally successful method has been the use of a single atom or small group of atoms somewhat heavier, or containing more electrons, than the atoms of the unknown carbonhydrogen skeleton of the molecule. The method was illustrated in a simple form in the structure determination of nickel phthalocyanine ${ }^{4}$.

With the compounds of organic chemistry it is generally fairly easy to insert a marker atom without unduly disturbing the structure. Halogen atoms may often be attached, or if the compound is an acid then heavy metal salts may be prepared. It is probably true to say that this general method has been utilized. in some form or another, in the great majority of $\mathrm{X}$-ray structure determinations of complex organic compounds during the past twenty years. The list of successful determinations is now so large that it would be tedious to try to enumerate them all. The structures of many natural products in the terpene and alkaloid fields, and several important antibiotics, have been determined in this way.

To begin with, the results have generally confirmed and put on an exact metrical scale what the chemist already knew, in outline at least. But as the technique of the subject advances the solution of chemically unknown structures is becoming more feasible. Already some notable contributions have been made. In the terpene field the structures of longifolene ${ }^{5}$. lanostenol ${ }^{6}$, and oleanolic acid ${ }^{7}$ have been solved. The structure of the alkaloid isocryptopleurine was solved by Fridrichsons and Mathieson ${ }^{8}$ without any. chemical data except the empirical formula, and the tropolone derivative nootkatin ${ }^{9}$ was recently solved in Glasgow.

Much the most striking recent result in this field, however, is the solution of the structure of vitamin $\mathrm{B}_{12}$ by Dorothy Crowfoot Hodgkin, John White and their many collaborators ${ }^{10}$. When this work began in 1948 there was no information about the chemical nature of the vitamin. But during the next eight years the chemical structure of various groups within the molecule was determined. A nucleotide-like group consisting of a benziminazole ribose phosphate, a propanolamine residue and various amide groups were discovered. There was also a cyanide group and, most important, a large fragment containing cobalt which it was suspected might be a porphyrin-like nucleus. There was, however, no very direct chemical evidence as to how all these groups might be linked together.

The presence of the cobalt-containing fragment and the possibility of a nearly planar porphyrin group (the crystals are strongly pleochroic) stimulated the $\mathrm{X}$-ray work. If a structure is not too complex, the presence of a single atom like cobalt, favourably situated, may sometimes lead to a very complete 
structure determination. But vitamin $B_{12}$ is vastly more complex than the compounds we have been considering, and with phases based on the cobalt contribution the density maps were very blurred and confused.

At this stage help was obtained from a study of the various other compounds that had been prepared by the chemists. In addition to the wet and air-dried vitamin, two other compounds proved to be most useful. These were the seleno-cyanate derivative, $\mathrm{B}_{12} \mathrm{SeCN}$, with a second heavy atom, and most important of all, a hexacarboxylic acid obtained by degradation (alkaline hydrolysis) which contained the porphyrin nucleus and its side chains. This crystalline fragment, obtained by Todd and his co-workers, was much less complex than the full vitamin $\left(\mathrm{C}_{46} \mathrm{H}_{58} \mathrm{O}_{18} \mathrm{~N}_{6} \mathrm{CoCl}\right.$ instead of $\mathrm{C}_{63} \mathrm{H}_{88} \mathrm{O}_{14} \mathrm{~N}_{14} \mathrm{PCo}$, but these formulæ were not established until later). Even this fragment, however, still represented an excessively complex structure determination.

The general method of attack was now to pursue all these structure determinations simultaneously. When some atoms or groups of atoms became fairly definite, and were confirmed by their appearance in the maps obtained from the other derivatives, then those atoms were inserted in the phasing calculations in gradually increasing numbers, which resulted in diagrams of increasing clarity and definition. The process of gradually deducing the structure by successive approximations is not, however, such a straightforward and easy task as it may sound. If a false atom is inserted in the phasing calculations it will appear in the place where it is put. But if false it will generally cause a peak of less than the expected height and be more poorly defined than would be the case with a genuine atom correctly placed. The work requires much judgment and intuition, and a continual process of checking against what is plausible on chemical grounds.

Another difficulty in this work, of course, is the tremendous amount of numerical calculation required. Each stage involves the evaluation of a triple Fourier series of several thousand terms at many tens of thousands of points throughout the unit cell. It is essentially a job for the large electronic computers ; and the later stages of the work owed much to Dr. Trueblood and the computer SWAC at Los Angeles.

In the latest work the positions of all the atoms in the molecule and of about 12 out of an estimated 24 molecules of water in the wet crystal have been ascertained. This very precise and beautifully determined structure should now form a basis for the better understanding of the biological activity of the vitamin, its relationship to the porphyrins and to porphobilinogen, and may also perhaps lead to its ultimate chemical synthesis.

This example was described at some length because it illustrates better than any other the enormous power of the X-ray method of analysis when applied to the solution of complex structures. When we remember the steady advances in technique which are taking place, and in particular the design of faster and more efficient electronic computers, we begin to realize what the effect of this new method on the future progress of chemistry is going to be. In determining the positions of atoms in space, which is to a large extent the basis of chemical knowledge, we have certainly moved a long way from those first fumbling steps which were taken about a century ago.
In the next paper, by Peter Pauling, on "A Rebirth of Inorganic Crystallography", a very brief review of the progress of X-ray analysis in the inorganic field was given. The early structural data, the Bohr atom and the new quantum mechanics allowed a theory of inorganic chemical bonding to be developed which extended the co-ordination theory of Werner and the covalent bond of Lewis. This went well on the way toward giving inorganic chemistry a unified theory, but it is certainly not complete. The postwar ligand field theory has had good success in explaining certain spectral phenomena and structural anomalies, but it is still not complete, as crystallographers and chemists have shown.

The impact of these theories has caused a renewed interest in inorganic chemistry and the structures of inorganic compounds. Inorganic chemistry still does not have a unified theory, though a means of thought and a direction in which to go are known, and it is certain that a complete theory will contain most important terms based on the spatial arrangement of the atoms as determined and checked by diffraction techniques.

In the last paper, on "How Molecules Fit Together", $H$. M. Powell said the fact that molecules fit together at all may seem remote from social significance, but an audience is itself, in a physical sense, composed of very little other than molecules fitted together, and the lecturer's every act of thought and speech involves rearrangement of his own constituent molecules. Such matters are very complex, but some help towards their understanding may come from the study of how simpler molecules pack in non-living material.

Molecules have shapes, some rigid, some flexible, determined by the distances between their linked atoms and the angles between the links. For packing purposes each atom in the atomic skeleton may be looked upon as surrounded by a negatively charged electron cloud, so that a molecule may be pictured as something like a balloon of possibly very irregular shape. Chemical reactions, growth, drug action, carcinogenic activity, and many other matters are bound up in various ways with molecular shape. In contrast to the liquid and gaseous stages, in which molecules behave in many ways as spheres, the crystalline pattern has the molecules in fixed positions which are determined by the manner in which their shapes can be packed. A general principle is that the molecules under the influence of their attractions tend to be closely packed, globules like piles of shot, cylinders like cigarettes or sloping like packs of books in a partly filled shelf, disks parallel like a pile of plates. More localized attractions between particular parts of neighbouring molecules, for example, strong spatially directed attractions through hydrogen in neighbouring water molecules, may act in a contrary sense, and by limiting the positions in which one may be placed relative to its neighbours, may lead to very open structures such as that of ice.

In some crystals molecules are bound, through hydrogen bonds or in other ways, to form larger aggregates. These sometimes may extend indefinitely in one or two dimensions, when the problem of packing them becomes that of arranging extended cylinders, ribbons, flat sheets, corrugated sheets, or related forms. If the aggregate extends indefinitely in three dimensions it constitutes the whole crystal and there is no further packing problem so far as that structure itself is concerned. 
Molecular structures of great geometrical complexity may be designed, and sometimes a close packing is impossible. Sometimes, molecules of two or more different kinds, if they are present in some suitable mixture, will together form a crystalline molecular compound. The manner in which molecules of different kinds thus fit together in regular or irregular arrays gives further information on the general principles of molecular packing.

Among the molecular packings in crystals, which were illustrated, were those in which similar or different shapes adjoin, and some where one shape encloses another. Others may interpenetrate like the links of a chain or become interlocked in a manner analogous to that used in a zip fastener. The dimen- sions and regularity of patterns formed by adjoining or enclosing molecules of two kinds can be related to the dimensions of the participating molecules.

\section{J. Monteath Robertson}

${ }^{1}$ Cox, E. G., Rev. Modern Physics, 30, 159 (1958).

${ }^{2}$ Abrahams, S. C., Robertson, J. M., and White, J. G., Acta Cryst., 2, 238 (1949). Mathieson, A. McL., Robertson, J. M., and Sinclair, V. C., ibid., $3,251(1950)$.

${ }^{3}$ Cruickshank, D. W. J., Acta Cryst., 9, 915 (1956); 10, 470 (1957).

' Robertson, J. M. and Woodward, I., J. Chem. Soc., 219 (1937).

${ }^{5}$ Moffett, R. H., and Rogers, D., Chem. and Indust., 916 (1953).

${ }^{8}$ Fridrichsons, J., and Mathieson, A. McL., J. Chem. Soc., 2159 (1953). "Abd El Rahim, A. M., and Carlisle, C. H., Chem. and Indust., 279 (1954).

${ }^{8}$ Acta Cryst., 8, 761 (1955).

- Campbell,R. B., and Robertson, J. M., Chem. and Indust., 1266 (1952). ${ }^{30}$ Proc. Roy. Soc., A, 242, 228 (1957).

\section{NEWS and VIEWS}

Botany at the Imperial College of Science and Technology: $\quad$ Prof. W. O. James, F.R.S.

THE news of the appointment of Dr. W. O. James to the chair of botany and headship of the Department at the Imperial College of Science and Tech. nology will be received with satisfaction by British botanists. He succeeds Prof. P. H. Gregory, who has been appointed head of the Department of Plant Pathology, Rothamsted Experimental Station (Nature, 181, 158; 1958; 172, 838; 1953). Dr. James began his botanical career as a student under Prof. Walter Stiles at what was then University College, Reading, and after obtaining a first-class honours degree in the University of London, for which Reading students then sat, he worked on problems of photosynthesis with the late Dr. F. F. Blackman at Cambridge. This was followed by a period at Rothamsted, where he examined the effect of potassium on carbohydrate metabolism. In 1928, Dr. James joined the staff of the Botany Department at Oxford, then under the direction of the late Prof. (afterwards Sir Arthur) Tansley. At Oxford, Dr. James has built up a very flourishing school of research in plant physiology, attention having been chiefly directed to the mechanism of plant respiration, for the elucidation of which, and the establishment of its essential identity with that in animal tissues, the work of James and his pupils has been largely responsible. This work has been described in numerous papers which have appeared mainly in the Pro. ceedings of the Royal Society, the New Phytologist and the Biochemical Journal. During the Second World War, as part of the Oxford Medicinal Plants Scheme, Dr. James devoted much time to the study of alkaloid metabolism and its relation to respiration. As well as his well-known monograph on "Plant Respiration", published in 1953, Dr. James is the author (jointly with Prof. A. R. Clapham) of "The Biology of Flowers", published in 1935, in which the authors dealt with the forms of flowers of a representative selection of species and their relations to insect visitors. His "Introduction to Plant Physiology" is also well known. Since 1932 Dr. James has been one of the editors of the New Phytologist.

Museum of Natural History, Washington:

Dr. A. C. Smith

DR. A. C. SMITH has been appointed director of the Museum of Natural History of the United States National Museum. He has been programme director for systematic biology with the National Science Foundation. Of special interest in this appointment is that, prior to his affiliation with the National Science Foundation, Dr. Smith was, for eight years, curator of the Division of Phanerogams in the Smithsonian Institution's Department of Botany. He now returns to the Institution to direct the Bureau, which includes the Departments of Anthropology, Zoology, Botany and Geology. In addition to directing the activities of the Museum of Natural History, Dr. Smith will continue his work in phanerogams, a research area of paramount importance. To date, Dr. Smith has published some 135 technical papers concerning this phase of botanical research. $\mathrm{H} \theta$ received his Ph.D. in 1933 from Columbia University in New York City. Thereafter, he was associated with the New York Botanical Garden and the Arnold Arboretum of Harvard University. In addition to study and research in England, France, Switzerland, Germany, Holland and the Scandinavian countries, he has participated in several botanical expeditions to Colombia, Peru, Brazil, Fiji, British Guiana, and the Lesser Antilles.

\section{Supreme Headquarters Allied Powers Europe :}

Dr. J. W. Abrams

Dr. John W. Abrams, of Ottawa, who is a member of the Canadian Defence Research Board and scientific adviser to the Chief of the Air Staff since 1954, has been loaned to Supreme Headquarters Allied Powers Europe (SHAPE) to undertake important duties in connexion with the scientific analysis and planning of Western European air defences. Succeeding him at R.C.A.F. Headquarters is Dr. J. C. Arnell, of Ottawa, the Board's director of plans. Both Dr. Abrams and Dr. Arnell assumed their new duties on September 1. General Lauris Norstad, supreme allied commander, Europe, requested Dr. Abrams's services because of his wide experience in the field of operational research and, in particular, with the various scientific problems relative to air defence systems. He played a prominent part in investigating the scientific aspects associated with the planning of Canada's air defence effort.

\section{Research on High-energy Nuclear Particles}

THE U.S. National Science Foundation has made a grant of 450,000 dollars to the University of Chicago for high-energy nuclear particle research with 